\title{
Discussion on "Optimum placement and characteristics of velocity- dependent dampers under seismic excitation" by Seyed Amin Mousavi and Amir K. Ghorbani-Tanha
}

Earthq Eng \& Eng Vib, 11(3): 403-414, DOI: 10.1007/s11803-012-0130-4

Izuru Takewaki ${ }^{\dagger}$

Department of Architecture and Architectural Engineering, Kyoto University, Nishikyo, Kyoto 615-8540, Japan

\begin{abstract}
The authors presented an interesting aspect in viscous or visco-elastic damper optimization under earthquake excitation. They also reviewed the research development in the field of passive damper optimization.

They introduced 'a drift-based formulation' in Section 2 to deal directly with the interstory drift which is an important performance measure in seismic design. However this formulation is essentially the same as the formulation to derive the story displacements and subtract the lower-story one from the upper-story one. This kind of formulation had already been proposed in a series of researches on damper optimization. For example, Eq. (18) is equivalent to the corresponding equation in Takewaki (1997, 1998, 1999a, b, 2000) and Eq. (21) is equivalent to the formulation in Takewaki (1999a). Many researchers refer to this formulation and employ that in their passive damper design problems (Aydin et al., 2007; Cimellaro, 2007; Cimellaro and Retamales, 2007; Viola and Guidi, 2009). Moreover, Eq. (22) is similar to the formulation in Takewaki (2001).

Some of these works published in 1998, 1999, 2000, 2007 and 2009 were not referred in the present paper. The authors did refer to Takewaki (1997) in the Introduction section. Actually, it should be cited at the point where the formulation is developed. In addition, the authors also presented 'an incremental optimization procedure' in Section 3.2. This incremental optimization procedure is similar to the formulation given in the references (Takewaki, 1997; 1998; 1999b; 2000). The minimum transfer matrix criterion in Section 3.1 seems to be a simple extension of Takewaki $(1997,1998)$ for the fundamental natural frequency.
\end{abstract}

\section{References}

Aydin E, Boduroglub MH and Guney D (2007), “Optimal

\footnotetext{
Correspondence to: Izuru Takewaki, Department of Architecture and Architectural Engineering, Kyoto University, Nishikyo, Kyoto 615-8540, Japan

Tel: +81-75-383-3294; Fax: +81-75-383-3297

E-mail: takewaki@archi.kyoto-u.ac.jp
}

†Professor

Received January 5, 2013; Accepted June 5, 2013
Damper Distribution for Seismic Rehabilitation of Planar Building Structures," Engineering Structures, 29: 176-185.

Cimellaro GP (2007), "Simultaneous stiffness-damping Optimization of Structures with Respect to Acceleration, Displacement and Base Shear," Engineering Structures, 29: 2853-2870.

Cimellaro GP and Retamales R (2007), "Optimal Softening and Damping Design for Buildings," Structural Control and Health Monitoring, 14(6): 831-857.

Takewaki I (1997), “Optimal Damper Placement for Minimum Transfer Functions," Earthquake Engineering and Structural Dynamics, 26(11): 1113-1124.

Takewaki I (1998), “Optimal Damper Positioning in Beams for Minimum Dynamic Compliance," Computer Methods in Applied Mechanics and Engineering, 156 (1-4): 363-373.

Takewaki I and Uetani K (1999a), “Optimal Damper Placement for Building Structures Including Surface Ground Amplification," Soil Dynamics and Earthquake Engineering, 18(5): 363-371.

Takewaki I (1999b), "Displacement-acceleration Control via Stiffness-damping Collaboration," Earthquake Engineering and Structural Dynamics, 28(12): 1567-1585.

Takewaki I (2000), “An Approach to Stiffness-damping Simultaneous Optimization," Computer Methods in Applied Mechanics and Engineering, 189(2): 641-650.

Takewaki I (2001), "Nonstationary Random Critical Excitation for Acceleration Response," Journal of Engineering Mechanics, ASCE, 127(6): 544-556.

Takewaki I (2007), Critical Excitation Methods in Earthquake Engineering, Elsevier Science.

Takewaki I (2009), Building Control with Passive Dampers: -Optimal Performance-based Design for Earthquakes-, John Wiley \& Sons Ltd. (Asia).

Viola E and Guidi F (2009), "Influence of the Supporting Braces on the Dynamic Control of Buildings with Added Viscous Dampers," Structural Control and Health Monitoring, 16(3): 267-286. 